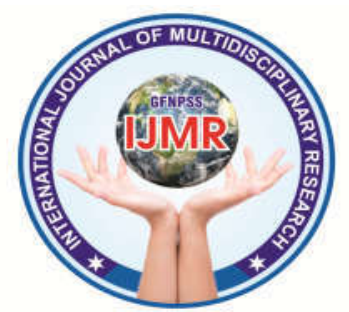

\title{
EVALUATION OF VERTICAL ROOT FRACTURES BY CONE BEAM COMPUTED TOMOGRAPHY
}

\author{
DR. BHAVNA BARTHUNIA ${ }^{1}$, DR. POULOMI BHAKTA ${ }^{2}$ \\ ${ }^{1}$ PROF. \& HOD, DEPT. OF ORAL MEDICINE \& RADIOLOGY, DASWANI DENTAL \\ COLLEGE \& RESEARCH CENTRE,RANPUR, KOTA, RAJASTHAN, INDIA \\ ${ }^{2}$ SENIOR LECTURER, DEPT. OF ORAL MEDICINE \& RADIOLOGY, DASWANI \\ DENTAL COLLEGE \& RESEARCH CENTRE,RANPUR, KOTA, RAJASTHAN, INDIA \\ Corresponding Email: poulomibhakta@gmail.com
}

\begin{abstract}
:
Background/Aim: The aim of this study was to investigate the occurrence of vertical root fracture using cone beam computed tomography (CBCT).

Methods: We reviewed the CBCT images of 41 patients who were examined and verified vertical root fracture. The characteristics of root fractures (pulpal vitality, existence of injury, kind of tooth, and core construction) that were considered to influence the occurrence of root fracture were investigated. The position of the tooth and the fracture direction were also examined. Diagnostic propriety of root fractures between intraoral radiography and CBCT was examined. Statistical analyses of each characteristic and the fracture direction were performed by Chi squared test. The position of the tooth and diagnostic propriety were analyzed by cross tabulation.
\end{abstract}

Results: The number of vertical root fracture was larger at non vital tooth $(P<0.001)$ and larger on non traumatized tooth $(P<0.001)$. There was not statistically significant difference among metal core, composite resin core, and no core to the occurrence of vertical root fracture. The number of vertical root fracture was largest on the premolar teeth $(P=0.022)$, and the anterior teeth fracture was larger on the upper teeth $(P=0.003)$. On the premolar teeth, the frequency of buccolingual fracture was larger than that of mesiodistal fracture $(P=$ 0.033). The vertical root fracture that was diagnosable by CBCT was larger in comparison to that by intraoral radiography $(P<0.001)$.

Conclusions: These results suggested that vertical root fracture easy to occur on non vital tooth, non traumatized tooth, and premolar tooth, and diagnosable using CBCT.

Key words: Cone beam computed tomography, diagnosis, vertical root fracture 


\section{INTRODUCTION}

Percentage of the dental patients with caries and periodontal disease has been decreased because of the development of the preventive dentistry, and the cause of tooth loss changed from caries or periodontal disease to root fractures. ${ }^{[1]}$ Root fractures could be occurred by the cause from endodontics, prosthetics, and trauma and so on. Enlargement of the root canal during the endodontic treatment can reduce fracture resistance by forming the microcracks, ${ }^{[2]}$ and the pressure of root canal obturation causes the extension of the microcracks. ${ }^{[3]}$ The preparation of the post after the endodontic treatment cause thinning of the root canal wall and reducing fracture resistance ${ }^{[4]}$ Concerning the influence of the post material to the root fracture, it is reported that the post material affected the fracture resistance of endodontically treated teeth ${ }^{[5,6]}$

The root fractures are broadly classified as vertical and horizontal root fractures. ${ }^{[7]}$ Vertical root fracture occurs along the tooth axis and most of the fracture extends from the apex of root to the coronal part and from the internal wall of root canal to the root surface. ${ }^{[8]}$ The vertical root fracture is reported to occur in endodontically treated teeth, ${ }^{[9]}$ and the incidence of vertical root fracture in endodontically treated teeth is shown between $3.7 \%$ and $30.8 \% .{ }^{[8]}$ Another study reported that the vertical root fracture in nonendodontically treated teeth is not uncommon in the Chinese population, and the incidence of vertical root fracture in nonendodontically treated teeth is shown over $40 \% .{ }^{[10,11]}$ Concerning the kind of the tooth, vertical root fracture is more prevalent in premolars and mesial root of mandibular molars. ${ }^{[12,13]}$ Root fracture teeth often lead a deep osseous defect around the fracture site. ${ }^{[14]}$ Thus, the cases of tooth loss caused by root fracture are increasing and a timely and definite diagnosis is important to avoid progressive alveolar bone loss. ${ }^{[15]}$

Concerning the diagnosis of root fracture, specific clinical signs or symptoms and radiographic features have been performed. ${ }^{[16]}$ However, the clinical signs or symptoms of root fracture are often unclear $^{[17]}$ For the diagnosis of root fracture by the radiographic features, periapical radiography has been used; however, periapical radiography is of limited use for the detection of fractures due to the compression of three dimensional anatomy into a two dimensional image, anatomical noise, and 


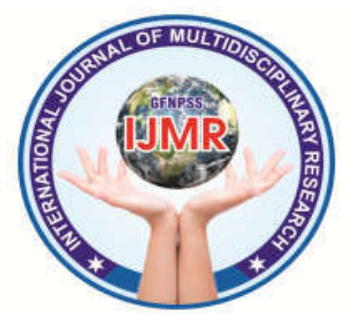

geometric distortion. ${ }^{[18]}$ On the other hand, cone beam computed tomography (CBCT) provides a three dimensional image viewing and has been widely used for the diagnosis or treatment planning. ${ }^{[19]} \mathrm{CBCT}$ has been reported to

Have higher accuracy than periapical radiography in the detection of root fracture [20] and shown its usefulness for the diagnosis of root fractures. ${ }^{[17,21,22]}$

It is important to prevent and treat root fracture to increase the life span of teeth. In order to that, we should know about the occurrence of the root fracture and the diagnostic method of the root fracture. The aim of this study was to investigate the occurrence of vertical root fracture using CBCT.

\section{METHODS:}

This retrospective study was approved by the ethics committee of our institution. We reviewed the CBCT images of 41 patients (17 male, 24 female; range age: 16-86 years, mean age: $62.0 \pm 15.9$ years) who were examined by CBCT for the diagnosis of root fracture and verified the vertical root fracture after extraction in our hospital . All patients were performed CBCT after intraoral radiography. The images were independently evaluated by two dentists and any discrepancies were resolved by consensus.

The characteristics of root fractures were investigated. Four factors (pulpal vitality, existence of injury, kind of tooth, and core construction) that were considered to influence the occurrence of root fracture were investigated. About pulpal vitality, the number of vital tooth and nonvital tooth was counted. Trauma experience was sorted out the tooth with a history of trauma (traumatized tooth) from the tooth without a history of trauma (nontraumatized tooth), and the number of each tooth was counted. Concerning to core construction, the number of metal core, composite resin core, and no core were counted. Kind of tooth was classified into anterior teeth, premolar teeth, and molar teeth, and the number of each tooth was counted.

Position of the tooth was also classified to upper teeth and lower teeth, and the number of each tooth on anterior teeth, premolar teeth, and molar teeth was counted. Fracture direction was classified to buccolingual and mesiodistal root fractures, and the number of each tooth on anterior teeth, premolar teeth, and molar teeth was counted. Diagnostic propriety of 


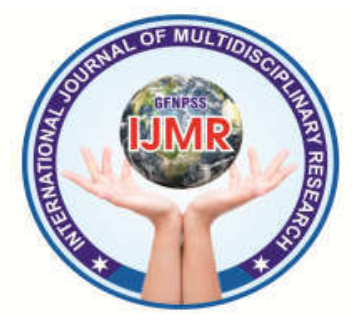

root fractures between intraoral larger in comparison with traumatized radiography and $\mathrm{CBCT}$ was also tooth $(\chi 2[1]=37.10, P<0.001)$. examined. The frequency of root fracture Concerning core construction, there was tooth diagnosable and impossibility of diagnosis were counted for each radiography technique (intraoral radiography and $\mathrm{CBCT}$ ).

Statistical analyses of each characteristic of root fractures and the fracture direction were performed by Chi squared test. Position of vertical root fracture tooth and diagnostic propriety of vertical root fractures were analyzed by cross tabulation. When statistically significance was found by cross tabulation, a residual analysis was performed. Statistical analysis was performed using statistical analysis software (SPSS 17.0, SPSS ), and differences of $\alpha<0.05$ were considered significant.

\section{RESULTS:}

Table 1 shows the characteristics of vertical root fractures. The result indicated that the occurrence of root fracture was different by pulpal vitality $(\chi 2[1]=23.44$, $P<0.001)$, and

the number of vertical root fracture was larger at nonvital tooth in comparison with vital tooth. On the frequency of vertical root fracture by trauma experience, the number of non traumatized tooth was no statistically significant difference among metal core, composite resin core, and no core to the occurrence of vertical root fracture $(\chi 2[2]=0.17, P=0.920)$. The number of vertical root fracture was different by the kind of tooth, and the number of the premolar teeth was largest $(\chi 2[2]=7.66, P=0.022)$.

Table 2 shows the position of vertical root fracture tooth with upper and lower teeth. The number of vertical root fracture was different between the upper and lower teeth $(\chi 2[2]=11.57, P=0.003, \mathrm{~V}=0.53)$, and the number of vertical root fracture on the anterior teeth was larger at the upper teeth. Although there were not statistically significant differences, the number of vertical root fractures on the premolar and the molar teeth tended to be larger at the lower teeth.

Table 3 shows the fracture direction of the vertical root fracture. The frequency of buccolingual fracture and mesiodistal fracture was not different at the anterior teeth $(\chi 2[1]=0.00, P=1.000)$ and the molar teeth $(\chi 2[1]=0.11, P=0.739)$. On the premolar teeth, the frequency of buccolingual fracture was larger than that 


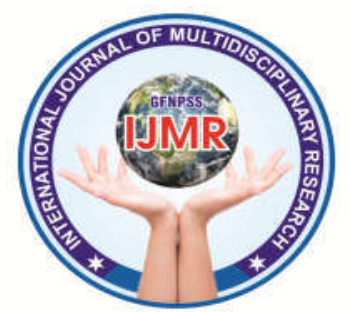

of mesiodistal fracture $(\chi 2[1]=4.55, P=$

$0.033)$.

Figure 1 shows the intraoral radiography image [Figure 1a] and CBCT image [Figure 1b] of one subject in this study that vertical root fracture (mesiodistal fracture) could not be diagnosed by intraoral radiography image but diagnosable by CBCT image. Figure 2 shows the intraoral radiography image [Figure 2a] and CBCT image [Figure 2b] of one subject in this study that vertical root fracture (buccolingual fracture) was diagnosable by intraoral radiography and $\mathrm{CBCT}$ images. Table 4 shows the diagnostic ability of vertical root fractures. The result indicated that the number of the vertical root fracture that was diagnosable

by $\mathrm{CBCT}$ was larger in comparison to that by intraoral radiography $(\chi 2[1]=45.22, P$ $<0.001, \mathrm{~V}=0.74)$.

\begin{tabular}{|c|c|c|}
\hline Parameters & Frequency of root fractures $(\%)$ & $P$ \\
\hline Pulpal vitality & $41(100)$ & \\
\hline Vital tooth & $5(12.2)$ & $<0.001$ \\
\hline Nonvital tooth & $36(87.8)$ & \\
\hline Trauma experience & $41(100)$ & \\
\hline Traumatized tooth & I (2.4) & $<0.001$ \\
\hline Nontraumatized tooth & $40(97.6)$ & \\
\hline Core construction & $36(100)$ & \\
\hline Metal core & $13(36.1)$ & 0.920 \\
\hline Composite resin core & II (30.6) & \\
\hline No core & $12(33.3)$ & \\
\hline Kind of tooth & $41(100)$ & \\
\hline Anterior teeth & $10(24.4)$ & 0.022 \\
\hline Premolar teeth & $22(53.7)$ & \\
\hline Molar teeth & $9(22.0)$ & \\
\hline
\end{tabular}

Table 2: Position of vertical root fracture tooth

\begin{tabular}{lcc} 
Parameters & Upper tooth (\%) & Lower tooth (\%) \\
\hline Anterior teeth & $10(100)^{\mathrm{a}}$ & $0(0)^{\mathrm{b}}$ \\
Premolar teeth & $9(40.9)$ & $13(59.1)$ \\
Molar teeth & $3(33.3)$ & $6(66.7)$ \\
\hline
\end{tabular}

asignificantly different to $(P<0,05)$

Table 3: Fracture direction of vertical root fractures

\begin{tabular}{lccc|}
\hline Parameters & $\begin{array}{c}\text { Buccolingual } \\
\text { fractures (\%) }\end{array}$ & $\begin{array}{c}\text { Mesiodistal } \\
\text { fractures (\%) }\end{array}$ & $P$ \\
\hline Anterior teeth & $5(50.0)$ & $5(50.0)$ & 1.000 \\
Premolar teeth & $16(72.7)$ & $6(27.3)$ & 0.033 \\
Molar teeth & $5(55.6)$ & $4(44.4)$ & 0.739 \\
\hline
\end{tabular}

Table 4: Diagnostic ability of vertical root fractures

\begin{tabular}{lcc}
\hline Diagnostic ability & Intraoral radiography (\%) & CBCT (\%) \\
\hline Diagnosable & $9(22.0)^{\mathrm{a}}$ & $39(95.1)^{\mathrm{c}}$ \\
Impossibility of diagnosis & $32(78.0)^{\mathrm{b}}$ & $2(4.9)^{\mathrm{d}}$ \\
\hline
\end{tabular}

${ }^{2}$ Significantly different to ${ }^{b}(P<0.05)$, cSignificantly different to $(P<0.05)$. $\mathrm{CBCT}$ : Cone-beam computed tomography
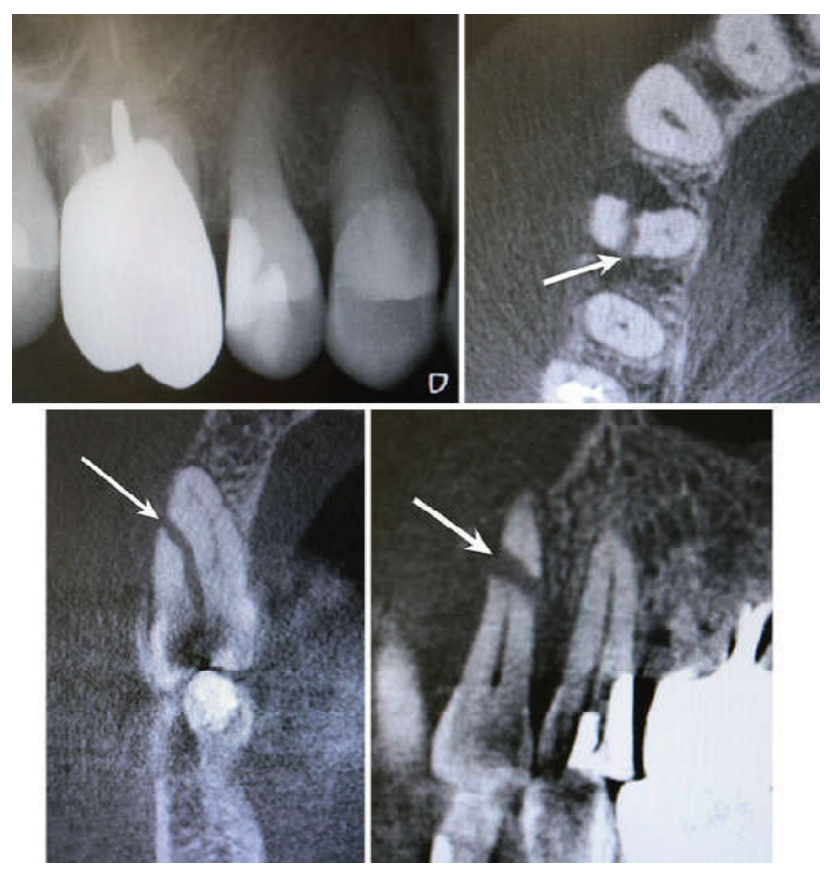

Figure 1: Intraoral radiography and cone beam computed tomography images that vertical root fracture (mesiodistal fracture) could not be diagnosed by 


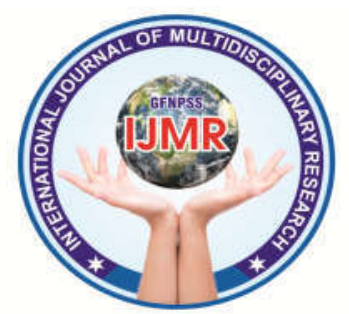

intraoral radiography image but $\square$ beam computed tomography image. diagnosable by cone beam computed Arrow indicates the part of root fracture. tomography image. (a) Intraoral radiography image. (b) Cone beam computed tomography image. Arrow indicates the part of root fracture. A. Axial image. B. Cross sectional multiplanar reformation (MPR) image. C. Parasagittal MPR image

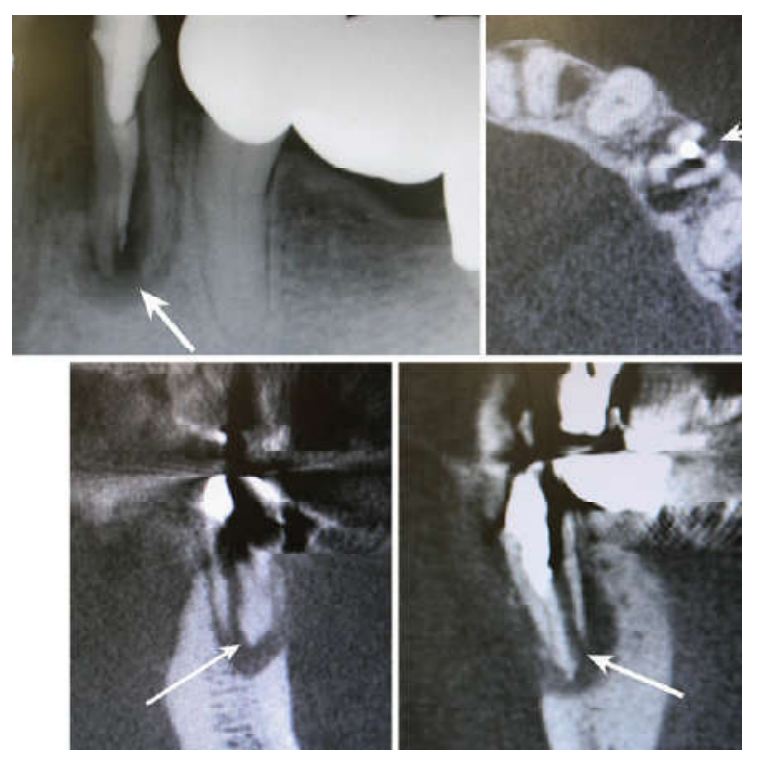

Figure 2: Intraoral radiography and cone beam computed tomography images that vertical root fracture (buccolingual fracture) was diagnosable by intraoral radiography and cone beam computed tomography images. (a) Intraoral radiography image. Arrow indicates the part of root fracture.

(b)Cone
A. Axial image. B. Cross
$\square$ sectional multiplanar reformation (MPR) image.
C. Parasagittal MPR image.

\section{DISCUSSION:}

The tooth loss caused by root fracture has been increasing instead of caries or periodontal disease. ${ }^{[1]}$ This study investigated the occurrence of the vertical root fracture and the diagnostic method of the vertical root fracture. Characteristics of vertical root fractures were investigated. Concerning pulpal vitality, the result showed that the occurrence of vertical root fracture was statistically significantly larger at non vital tooth in comparison with vital tooth. This result was consistent with the results of the previous reports. ${ }^{[24,]}$ The frequency of vertical root fracture was larger on non traumatized tooth in comparison with traumatized tooth. Horizontal root fractures are the most common type of traumatic injuries. ${ }^{[7]}$

The result of this study would support the following recommendations to the frequency of vertical root fracture that is larger on non traumatized tooth, and traumatized tooth tends to be horizontal root fractures ${ }^{[7]}$

\footnotetext{
591 GFNPSS-International Journal of Multidisciplinary Research, Volume 2, Issue 4, April 2021
} DOI: 10.46376/IJMR/2.4.2021. 


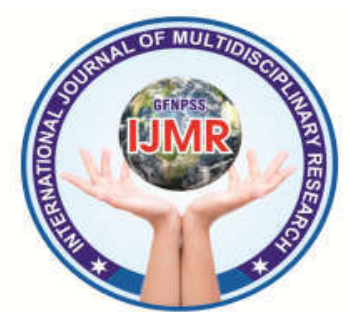

Thus, there are no unified views propriety of vertical root fractures was concerning fracture resistance by core materials. In the limit of this study, it was indicated that core construction would not influence the occurrence of vertical root fracture. The number of vertical root fracture was largest at premolar teeth. The result of additional investigation that analyzed the difference between the upper teeth and lower teeth indicated that all vertical root fractures on the anterior teeth were the upper teeth. On the other hand, the number of vertical root fracture on the premolar and the molar teeth tended to be larger at the lower teeth. Previous reports mentioned that vertical root fracture was more prevalent in premolars and mesial roots of mandibular molars ${ }^{[12,13]}$ The result of this study was consistent with these reports. ${ }^{[12,13]]}$ were applied. Therefore, the number of vertical root fracture would be largest on the premolar teeth. Concerning the frequency of vertical root fracture between the buccolingual and mesiodistal fractures, the number of buccolingual fracture was significantly larger on the premolar teeth. The reason of this result would be caused by the anatomy of the premolar tooth. Therefore, the premolar tooth would be suffered excessive forth to the buccolingual direction. The diagnostic statistically significantly different between intraoral radiography and $\mathrm{CBCT}$, and the diagnostic ability by CBCT was significantly greater than that by intraoral radiography. Only two cases were impossibility of diagnosis by $\mathrm{CBCT}$ because of metal artifacts. CBCT can provide a better visualization of fracture line through multiplanar reconstructed images (axial, coronal, and sagittal planes). Intraoral radiography is two dimensional radiograph; therefore, overlap of adjacent structures causes limits of the visualization of fracture line ${ }^{[8]}$ In the limit of this study, vertical root fracture could be detected by intraoral radiography only for the root fracture that the root was separated clearly. On the other hand, CBCT could detect vertical root fracture even if the root was not separated and the fracture line was not recognized by intraoral radiography. These results supported the previous study which indicated that CBCT was significantly more accurate than periapical radiography for the detection of vertical root fractures ${ }^{[17]}$

In the limit of this study, it was suggested that vertical root fracture would be easier to occur on non vital tooth, non traumatized tooth, and premolar tooth. On 


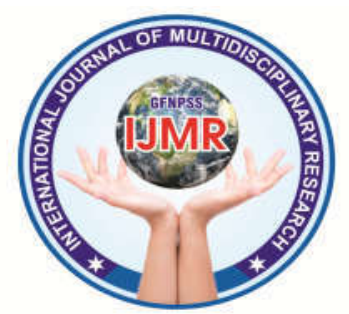

premolar tooth, the fracture direction tended to be buccolingual direction. CBCT showed high diagnostic ability in comparison to intraoral radiography. In the case that vertical root fracture was doubtful, it was suggested to check the characteristics of root fractures and use $\mathrm{CBCT}$ for the diagnosis of root fracture.

\section{REFERENCES:}

1. Axelsson P, Nyström B, Lindhe J. The long term effect of a plaque control program on tooth mortality, caries and periodontal disease in adults. Results after 30 years of maintenance. J Clin Periodontol 2004;31:74957.

2. Wilcox LR, Roskelley C, Sutton T. The relationship of root canal enlargement to finger spreader induced vertical root fracture. J Endod1997;23:5334.

3. Shemesh H, Wesselink PR, Wu MK. Incidence of dentinal defects after root canal filling procedures. Int Endod $\mathrm{J}$ 2010;43:995-1000.

4. Standlee JP, Caputo AA, Holcomb J, Trabert KC. The retentive and stress distributing properties of a threaded endodontic dowel. J Prosthet Dent 1980;44:398, 404.
5. Kaya BM, Ergun G. The effect of post length and core material on root fracture with respect to different post materials. Acta Odontol Scand 2013 ;71:1063-70.

6. Barcellos RR, Correia DP, Farina AP, Mesquita MF, Ferraz CC, Cecchin D.Fracture resistance of endodontically treated teeth restored with intraradicular post: The effects of post system and dentine thickness.J Biomech 2013;46:2572-7.

7. Malhotra N, Kundabala M, Acharaya S. A review of root fractures : Diagnosis, treatment and prognosis. Dent Update 2011; 38:615-6,619-20, $623-4$.

8. Hekmatian E, Karbasi Kheir M, Fathollahzade H, Sheikhi M. Detection of vertical root fractures using cone beam computed tomography in the presence and absence of gutta percha.ScientificWorldJournal2018;20 18:1920946:1-5.

9. Komatsu K, Abe Y, Yoshioka T, Ishimura H, Ebihara A, Suda H.Differential diagnosis of vertical root fractures using reconstructed three-dimensional models of bone 


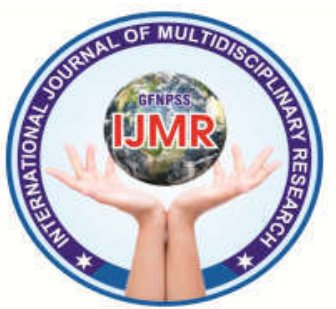

defects. Dentomaxillofac Radiol 2014 ;43:20140256:1-9.

10. Chan CP, Lin CP, Tseng SC, Jeng JH. Vertical root fracture in endodontically versus nonendodontically treated teeth: A survey of 315 cases in Chinese patients. Oral Surg Oral Med Oral Pathol Oral Radiol Endod 1999;87: $504-7$.

11. Wang P, Yan XB, Lui DG, Zhang WL, Zhang Y, Ma XC. Detection of dental root fractures by using cone-beam computed tomography. Dentomaxilla ofac Radiol 2011;40: 290 -8.

12. Ezzodini Ardakani F, Razavi SH, Tabrizizadeh M. Diagnostic value of cone-beam computed tomography and periapical radiography in detection of vertical root fracture. Iran Endod $\mathbf{J}$ 2015;10:122-6.

13. Safi Y, Aghdasi MM, Ezoddini Ardakani F, Beiraghi S, Vasegh Z. Effect of metal artifacts on detection of vertical root fractures using two cone beam computed tomography systems. Iran Endod J 2015;10:193-8.

14. Walton RE, Michelich RJ, Smith GN. The histopathogenesis of vertical root fractures. J Endod 1984;10:48-56.
15. Tsesis I, Beitlitum I, Rosen E. Treatment alternatives for the preservation of vertically root fractured teeth. In: Tamse A, Tsesis I, Rosen E, editors.Vertical Root Fractures in Dentistry. Heidelberg: Springer; 2015 .p. 97-107.

16. Walton RE. Vertical root fracture: Factors related to identification. J Am Dent Assoc 2017;148:100-5.

17. Brady E, Mannocci F, Brown J, Wilson R, Patel S. A comparison of cone beam computed tomography and periapical radiography for the detection of vertical root fractures in nonendodontically treated teeth. Int Endod J 2014;47:735-46.

18. Patel S, Dawood A, Whaites E, Pitt Ford T. New dimensions in endodontic imaging: Part 1. Conventional and alternative radiographic systems. Int Endod J 2009;42:447-62.

19. Shukla S, Chug A, Afrashtehfar KI. Role of cone beam computed tomography in diagnosis and treatment planning in dentistry: An update. J Int Soc Prev Community Dent 2017;7:S 12536.

20. Talwar S, Utneja S, Nawal RR, Kaushik A, Srivastava D, Oberoy SS. 
Role of cone beam computed tomography in diagnosis of vertical root fractures: A systematic review and meta-analysis. J Endod2016;42:12-24.

21. Byakova SF, Novozhilova NE, Makeeva IM, Grachev VI, Kasatkina IV.The accuracy of CBCT for the detection and diagnosis of vertical root fractures in vivo. Int Endod $\mathrm{J}$ 2019;52:1255-63.

22. Chavda R, Mannocci F, Andiappan M, Patel S. Comparing the in vivo diagnostic accuracy of digital periapical radiography with cone-beam computed tomography for the detection of vertical root fracture.J Endod 2014;40:1524-9.

23. Sue M, Oda T, Sasaki Y, Ogura I. Age-related changes in the pulp chamber of maxillary and mandibular molars on cone-beam computed tomography images. Oral Radiol 2018;34:219-23.

24. Carter JM, Sorensen SE, Johnson RR, Teitelbaum RL, Levine MS. Punch shear testing of extracted vital and endodontically treated teeth.J Biomech 1983;16:841-8. 